\title{
Factors that hinder the academic performance of the nursing students who registered as first years in 2010 at the University of Namibia (UNAM), Oshakati Campus in Oshana, Namibia
}

Lusia N. Pinehas , Ester Mulenga, Julia Amadhila

School of Nursing, University of Namibia, Oshakati, Namibia

Received: December 18, 2016

DOI: $10.5430 /$ jnep.v7n8p63
Accepted: January 19, 2017

Online Published: March 14, 2017

\begin{abstract}
The University of Namibia (UNAM) is the only national university in Namibia that was established in 1992. It offers diploma and degree courses. The Bachelor of Nursing Science (Clinical) (Honours) was introduced in 2008 after the Diploma in Comprehensive Nursing Science was phased out. This degree is offered over the period of four years full-time. Students are allocated to the clinical practice throughout the training to acquire the relevant nursing skills. At the time of research the course was offered at two campuses only namely Windhoek and Oshakati. The total number of students who were admitted in 2010 was 83 , but at the time of the research when they were in their fourth year, there were only 59. The difference of 24 was the students who could not make it to the fourth year and finish in the prescribed time frame. The lecturers were concerned with the poor performance of the students, the increased number of students with some modules behind, and the overcrowding of some classes. The purpose of the study was to identify, explore and describe the factors that hinder the academic performance of the nursing students at the UNAM Oshakati campus. The study was conducted among nursing students who registered for the Bachelor of Nursing Science (Clinical) (Honours) in 2010. The study was qualitative, exploratory, descriptive and contextual in nature using non-probability purposive sampling. The findings revealed that the academic performance of student nurses at the University of Namibia Oshakati campus is influenced by both internal and external factors. However, external factors are many compared to internal factors. External related factors comprise of teaching and learning, insufficient resources, lack of university accommodation, curriculum related and socio-economic factors. Teaching and learning related factors include use of one teaching strategy, language barriers, inadequate support and labeling of students by lecturers. On the other hand, insufficient resources are unavailability of the bookshop on campus, insufficient prescribed textbooks, poor internet facility, lack of space and less equipped library. Curriculum related factors include overloaded examination time table, huge scope of test, study day system and module pre-requisites, while socio-economic factors are problems in relationships, peer influence, financial problems and pregnancy while studying. Internal factors comprise of students' attitude and lack of self-discipline among some students. Those factors result in increased number of students with some modules behind, overcrowding of some classes, increased student-lecturer ratio and some students not completing their studies within the prescribed time frame.
\end{abstract}

Key Words: External factor, Internal factor, Hinder, Academic performance, Nursing student

*Correspondence: Lusia N. Pinehas; Email: lpinehas@ unam.na; Address: School of Nursing, University of Namibia, Oshakati Campus, Namibia. 


\section{INTRODUCTION}

Nursing is an art and science that has been in practice since human evolution, so does nursing education. The ancient approach of nursing education hasn't been well organized and formalized. However, with development, nursing education has become a well-organized branch of the nursing profession. Student nurses are trained to serve the sick and all people who are in need of health care in hospitals and in the community. The road walked by student nurses on their way to achieve their educational goals, might be filled with multiple factors that influence their academic performance, such as, financial constraints, inadequate time for study and lack of proper accommodation. Nursing education in Namibia was started in 1911 by the Finish Missionaries after they had arrived in the then Owamboland during the preindependent era. Missionaries played a very important role in the development of nursing education in Namibia. Nurses were taught in their mother tongue if not in Afrikaans. ${ }^{[1]}$

In 2008 a four year Bachelor of Nursing Science (Clinical) (Honours) degree program was introduced. The program is offered, at the University of Namibia's two campuses namely Main Campus in Windhoek and Oshakati under the School of Nursing and Public Health of the Faculty of Health Sciences. In 2010 the total number of student nurses admitted to the Bachelor of Nursing Science (BNSC) (Honours) (Clinical) course was 83 , but only 59 student nurses reached their final year with no modules behind. The academic staff at Oshakati campus bemoaned a decline in the level of student nurses performance and a decrease in the number of student nurses promoted into the next level of study in this group.

\section{MeTHODS}

A qualitative, exploratory, descriptive and contextual research design was used in this study. The population for this study consisted of 83 student nurses who registered as first years in 2010 at UNAM, Oshakati Campus. A nonprobability purposive sampling method was used. Eleven students which comprise of 9 females and 2 males were interviewed in three focus group discussions of 3 to 4 participants in each group, using an interview guide containing only one main question which was "What are the factors that enhance and hinder your academic performance since you started this program in 2010?" Then the interview was followed by probing questions such as "what do you mean by saying student discipline affects the study timetable, how does family influence academic performance, you talked about students' attitudes, what type of attitudes can influence your performance, anything else?" Probing questions were asked based on the responses that needed clarifications. Interviews were recorded and field notes were taken. Permission to conduct the research was sought from the management of UNAM, Oshakati campus and approval was granted which is equivalent to Institutional Review Board (IRB) approval. The research process was explained to the participants. The issues of privacy, anonymity and confidentiality were ensured. Participation was voluntary; therefore, some participants withdrew from the study. Informed consent was signed for both participation and recording of the information. Measures to ensure trustworthiness were ensured through member check whereby the recorded interviews were played back to the participants.

\section{RESULTS}

The results presented below are internal and external factors that hinder the academic performance of the student nurses who registered for Bachelor of Nursing Science (Clinical) (Honours) in 2010. External related factors comprise of teaching and learning, insufficient resources, lack of university accommodation, curriculum related and socio-economic factors. Internal factors include students' attitude and lack of self-discipline among some students. The factors that enhance their academic performances will be presented in a separate article.

\subsection{External factors}

\subsubsection{Teaching and learning related factors}

Some participants felt that the teaching strategy more especially the lecture method where by the lecturer gives a little information does not benefit all the students: “... they just give a brief overview of the information..."

There are some lecturers who are not able to explain and elaborate due to difficulties of the language: “.... they are willing but they just can't ... they can't make a person understand... also when lecturers change modules it affects the student performance when the lecturer is not knowledgeable about the specific module... it is also a new thing to her/him... the lecturer just read what is on that paper and not giving explanation or examples or elaborate."

Some lecturers according to the participants become furious when asked questions: "sometimes some of the lecturers they will get furious at students."

Some lecturers again, explain in vernacular language which makes foreign students not to understand what is said: “...explain or answer a question in a vernacular language to make you understand more... there are those students who do not understand it." With the above statement students refer to foreign students who are admitted to do the course with Namibian students.

Some students repeated some modules taught by certain 
lecturers but if that lecturer changes to teach another level, students will pass the module: “... some students keep on repeating one subject with one lecturer.. when the lecturer change e.g. move to second year that student will pass that subject."

Participants felt that lecturers labeled students and when they came to class they judged the student according to what they heard.

According to participants, some lecturers have personal issues against some students: “... they are arguing with those students ... they don't care ...they ask personal issues ... scare students that ... do you know that your husband will leave you ...?"

Participants felt that students, especially slow learners need more support from lecturers. They (participants) felt that lecturers should put more effort on slow learners to make them (students) catch up: “... lecturers are not putting more efforts on slow learners... they don't care for those slow learners... may be arrange to give them extra classes."

Participants felt that students need to support each other on the way to help others to cope with personal, financial and social difficulties so that they can also perform well academically: “. . . there is lack of support team on campus ... a team that a student can talk to when having problems ... to cope with their problems."

\subsubsection{Insufficient resources}

The unavailability of the bookshop on campus has a negative influence on nursing students' academic performance: "... no bookshop on campus, hence there is a need to have Van Schaik book shop on campus... as a result you cannot access to the information."

Lack of prescribed books has a negative influence on the academic performance: “... the prescribed books are so scarce, only about $20 \%$ of students manage to have prescribed books ... having difficulties in getting the books ... we make arrangement with friends in Windhoek... just buy books and send them to us... it is quite costly... it takes long to get study materials... this affects our academic performance negatively..."

Participants indicated that the library is less equipped, and the books do not meet their study needs: “... books in the library are not enough... they are kept on reserve shelf... only 20\% of students benefit from the books which are available in the library... the rest are left out without information ... there is only 1 or 2 prescribed book in the library". Furthermore they (participants) felt that less equipped library contributes to their poor performance: “... the information

Published by Sciedu Press on the notes (from lecturers) is always limited ... if you fail to understand those notes, no extra books where you can study... you will perform poorly... students who borrow the book will book it for the whole year... those people in the library are not aware of that same student using the book for the whole year... the copies provided by lecturers do not have all the necessary information... do not have all the information ... they end up performing poorly."

Hard copies that are provided by some lecturers for the class disappear without reaching all the students: “... sometimes they (lecturers) give 1 or 2 copies... to the class representative... the class representative gives it to one student from there it disappears."

Although UNAM introduced the free internet facilities on campus, participants are still experiencing problems with internet services: “... there is a lot of trouble in accessing the internet... it goes off for the whole week... you can spent an hour waiting for that computer to process ... it is slow."

The time that students $\log$ on the internet is short: “... like you want to use the internet, before you finish you are already logged out... and restart again... it is time consuming."

Computers are not enough and slow on processing the information: "... one has to wait for that computer to process... just wasting of time in most of them not working”.

Poor service with regard to making photocopies affects their academic performance: “... sometimes you go to photocopy machine, put your money... the machine is not working well..." Photocopy machines are not reliable: “... sometimes you want to make copies and the photocopy machine is not working".

Participants felt that sometimes the photocopy machine is cheating them: “... you put your money today tomorrow there is no credit... the money disappears from the machine... somehow somewhere the system is really cheating us." Participants felt that it is not fair that the machine is cheating on them because they have no money: "... to lose 20 or 50 dollars from your pocket, it is a lot."

The library on campus does not have enough space; it is small to accommodate many students for study especially during examination time: “... some students cannot study in the library... they go study at houses due to lack of space in the library... we don't fit in the library... the temperature is cold ... they don't adjust the temperature."

Participants do not receive enough technical support: “... he [technician] will tell you that he will get the statement out... he [technician] will tell you that you made copies while you do not... you just put money and just go to the copy machine 
you will find zero balance, no solution.”

\subsubsection{Lack of University accommodation}

Participants felt that if they were provided with accommodation at the campus they could perform better academically: “... some of them [students] struggle to get accommodation... some do not have money to pay rent... they end up staying in the environment not conducive for learning, as a result they perform poorly... if UNAM could have accommodation here [at the campus], students can study in the library until it closes... so we use to rent in those squatter camps around the campus or stay with our relatives and it is difficult to be in that house."

Relatives also do not allow a student to have the electricity on till late: “... sometimes you want to study (during the evening) and the person (owner) says switch off the electricity... and sometimes there is no electricity..."

\subsubsection{Curriculum related factors}

According to participants pre-requisite makes a student to be behind: “... we are not informed it, only came up during registration ... it was really bad ... we fail to understand it."

Some participants felt that the study day system that was used in their first, second and third year also influenced the students' performance negatively: “... you have to come from the hospital and... you write a test ... you didn't even get enough time to prepare ... at the end of the year your [continuous assessment] CA marks are low..."

Participants felt that some lecturers give them scope for the tests but then the scope is huge in such a way that the student will not cope to study for that specific test. Also when only ten questions are asked: “... a very huge scope ... only one question with 30 marks ...you end up missing ...the scope was so huge..."

Participants felt that the examination time table influences their academic performance poorly especially when two modules are often written in one day or consecutively: “... when in a day you write two subjects... it is just difficult to cope ...you will not get enough time to study. . it is really killing to the slow learners or students... to study two subjects written in the same day."

\subsubsection{Socio-economic factors}

Participants in the study indicated that there are some students who experience problems in their relationships and this can influence their academic performance negatively: “... some people have problems at home... in their relationship... those things have an influence on the academic performance."

They also indicated that becoming pregnant while you study might affect the student's performance: “... pregnancy rate is high, such things also influence on the academic performance... you cater for yourself and for the new baby... sometimes nannies have issues.... now you do not have to go to school... you have to look after the baby...there are some who did not make it to the next level ... they remained behind."

According to the participants, some students acquire negative behaviour from others that will influence their academic performance in a negative way: “... we tend to learn negative things from others... sometimes you go with friends, you drink alcohol or you smoke... you are not going to come up with anything or gaining anything from that class, either you are drunk, sleeping or tired and it affects your performance. . when you come to class you are not paying attention at all ... it is true that peer pressure can influence the student performance."

A student might feel bored and tempted when seeing others going out and join them and end up not performing well: “... you see others going out and you think you have a boring life... you start joining others and end up not performing well." Some students use to come with good manners, but after socializing with others they changed and start drinking and performing poorly: “... other negative factors are alcohol and drug abuse among students.”

Students who do not have enough money perform poorly. According to the participants also students who do not have loans perform poorly because they cannot buy prescribed books: “... students who do not have loans to buy recommended books... this leads to performing poorly... some modules do not have prescribed books, students have to rely on what they are getting from their lecturers, as a result they will perform poorly."

\subsection{Internal factors}

Participants felt that when a student lacks self-discipline he/she might be tempted when studying in the bedroom: “... then studying in the bedroom is just difficult ... there is a bed tempting you ... you want to sleep ... your performance will be affected".

According to the participants, some students develop negative attitudes towards their own studies. Some students are reluctant and do not put more effort in their own study. According to them, lecturers cannot keep on pulling while the student's side is quiet: “... some lecturers use to write 'come see me' after the student failed a test but the student don't go to see the lecturer."

Some students, because of bad influence and labeling of lecturers, start to say lecturer are bad but then in many times 
students interpret it wrongly, while it is the students who do not put effort in their studies: "... then you think is it real the lecturer who is not good or the student who did not put effort to finish the practical book."

According to the participants, it seems that some students are not aware of the existence of or do not make use of the social worker or student counselor on campus when they have problems: “... students are not really aware of those people who can help them on social issues... a lecturer/management can refer the student to the counselor when the performance is not really good ... or referring students to other nurses to talk to them."

According to the participants' description, when senior students inform junior students that a certain lecturer is not good, then that specific lecturer will end up not well for the student community: “. . . like from our previous students there was a story that a lecturer is not good what ... what, then the lecturer will end up not good to every student." Students will end up judging a certain lecturer according to stories that they heard: “... but you are just judging from what you heard from other students.”

Participants also felt that even when a student has a real study problem affecting his/her study of which he/she is aware of, when marked by that 'specific' lecturer who was gossiped that student will end up feeling marked unfairly: “... even that person (lecturer) marked you (student), you (student) end up having a problem even though you know you did not write up something ... you just have a problem with that lecturer."

Some students blamed lecturers for their own mistakes: “... students have a tendency of blaming lecturers for their own mistakes ... some call lecturers names ... they say 'this lady'... and when they go to the class they already colored that lecturer.. every time the lecturer tells you to do something you refer to what you have heard about her/him."

\section{DisCUSSION}

Recorded data was transcribed verbatim and field notes where incorporated. Tesch's method of open coding was adopted during analysis whereby transcriptions were read and re-read to get sense of the data. Topics related to each other were grouped together and themes were derived from those topics. The themes are described under external and internal factors.

\subsection{External factors}

\subsubsection{Teaching and learning related factors}

Participants felt that teaching and learning factors such as teaching strategies, student-lecturer relationship and

Published by Sciedu Press communication barrier hinder their academic performance. Ganyaupfu $^{[2]}$ emphasizes that lecturers should create an atmosphere conducive to learning in order to enhance the development of students' learning experiences. Student-centered learning environment produces higher level learning outcomes more efficiently than a traditional teacher-centered environment. $^{[2]}$ According to Mbugua and colleagues ${ }^{[3]}$ lecturers should use effective teaching methods and use studentcentered approach to allow the students to be actively involved during classroom communication. Rane ${ }^{[4]}$ also indicates that lecturers should increase their teaching methodology and master the class in order to increase student academic achievement. In addressing the issue of problems with the teaching methods, Tom and colleagues ${ }^{[5]}$ emphasize that there is a need for lecturers and students to sit together, share their expectations, believes and jointly develop strategies that increase the students' success.

Ganyaupfu ${ }^{[6]}$ indicates that lecturer competence in teaching is a combination of paradigms in the sense that it measures a variety of interrelated aspects in teaching; which includes subject matter expertise, lessons preparation, lesson presentation and effective communication. The influence of lecturer's teaching competence on students' learning outcomes is measured through students' academic achievements. ${ }^{[6]}$ Lack of knowledge in the course material by the lecturer leads to frustration among the students and when their expectations are not fulfilled their academic performance is compromised and they develop an attitude against the lecturer. ${ }^{[3]}$

In a student-lecturer relationship the lecturer's attitude towards the student in a certain subject has an influence towards the academic performance of that student. ${ }^{[3]}$ According to Gillespie $^{[7]}$ student-lecturer relationship is the key to humanistic nursing education. This relationship should be well defined and based on sound professionalism which includes aspects such as professional caring, competence, wholeness, interconnectedness, compassion, confidence, conscience and commitment from both the lecturer and the student. ${ }^{[7]}$ Furthermore, Gillespie ${ }^{[7]}$ indicates the positive effects that the student-lecturer-relationship has on the academic performance of the student as well as the "maximization of positive student outcomes and the support in student personal and professional growth".

Students need to see that their lecturers care about them in the classroom, the office, on campus as well as off campus including the clinical setting and they need to recognise and feel that care. ${ }^{[7]}$ When conflicts and frustrations arise both students and lecturers alike need to understand that those conflicts are part of any health relationship and should be worked on to enrich the student-lecturer relationship. ${ }^{[7]}$ 


\subsubsection{Insufficient resources}

Participants felt that lack of prescribed books and less equipped library hinder their academic performance. Schools without basic facilities and resources such as prescribed textbooks often have low academic performance. ${ }^{[8]}$ Owoeye and Yara $^{[9]}$ indicate that the main purpose of a school library is to make all books, periodicals and other reproduced materials available to the students. They further indicated that school libraries may not be effective if the books therein are not adequate and up to date.

Participants felt that the space in the library has an influence on their academic performance in such a way that it is not enough. The library environment should have comfortable chairs and rich in literature with plenty of books, computers and other learning aids that help the student to perform well. ${ }^{[10]}$ Students need sufficient space for their study so that they do not need to squeeze themselves together. ${ }^{[10]}$ Mokgaetsi ${ }^{[11]}$ states that the students will not perform well academically if the environment has an uncomfortable temperature because the students' concentration deteriorates, feel either tired or drowsy and their cognition, intellectual productivity and creativeness will be affected. Listphoria ${ }^{[12]}$ states that physical learning environment such as inadequate heating and air conditioning has an influence in the students' learning and academic performance no matter how skilled and effective the lecturer is. Tanvi ${ }^{[13]}$ indicates that a conducive environment facilitates learning, therefore lecturers and administrators should provide students with such environment.

Participants in this study indicated that they experience problems with internet services and the log on time is short. Internet provides various services including email, instant messaging, social networking, tweeting and video conferencing, information searching and blogging services that promote learning. ${ }^{[14]}$ Furthermore, Ogedele ${ }^{[14]}$ indicates that there is a positive correlation between internet usage and academic achievement.

\subsubsection{Lack of University accommodation}

Participants in this research revealed that their academic performance is influenced by lack of accommodation at the university. A university environment is supposed to be an environment that is appropriate, safe, hygienic and conducive for learning with enough space and physical facilities that enhance learning. Ali and colleagues ${ }^{[8,10]}$ indicate that the residential area or hostel life is beneficial to the performance of a student because it provides an environment that is conducive for the student to study. The environment that is conducive is the one that allows the students to sit down or stooping as well as walking from time to time while studying, to be focused in pursuing their dreams but not the environment that tempt them to lie while studying. ${ }^{[10]}$

In South Africa for instance, "the demand for student accommodation in 2012 spikes leading to lack of proper accommodation especially for students who came from far areas to study in big cities and leading to chronic shortage of safe, secure and affordable accommodation." ${ }^{[15]}$ The report continues to reveal that private sector in that country became a "significant contributor and stakeholder". ${ }^{[15]}$ in the unregulated nature of accommodation in such a way that they exploit the students by charging them high fees for rental. This means that accommodation that was built by the private sector led to exploitation of students. It was further reported that "severe shortage of accommodation in universities and long commute distance compromise academic performance of students" ${ }^{[15]}$ Ali and colleagues ${ }^{[8]}$ suggest that students need to be provided with an environment that benefits their academic performance.

\subsubsection{Curriculum related factors}

Participants in this study felt that pre-requisite has an influence on their study. At the University of Namibia, a pre-requisite refers to a module that must be passed first before the student can register the next module. ${ }^{[1]}$ Penprase and colleagues ${ }^{[16]}$ state that it is true that passing a certain subject (pre-requisite) prepares the student to understand the other subject, but it influences the academic performance of the student's critical thinking because only a student with a sound background will master the content. The student who lacks interest in a subject or who just learn the subject because it is a pre-requisite to the other subject or just to complete the course will experience difficulties in mastering the specific subject. ${ }^{[16]}$ Furthermore, it was suggested that in order to overcome the influence of pre-requisites on the academic performance of the students the curriculum needs to be reviewed and changed now and then. ${ }^{[16]}$

Participants further indicated that the scope of test influence their academic performance. Miller and colleagues ${ }^{[17]}$ state that the preparation for the test can entail many dimensions which include the maintenance of good study habits, completing and submitting assignments on time. Students need to have a clear understanding of the work expected and communicate to the lecturer if any additional help is needed. Furthermore, it was indicated that students should be knowledgeable on what to do and what not to do when preparing and writing a test. ${ }^{[17]}$ Students should start by planning and preparing ahead of the test or examination by keeping reading, review or pay attention to hints that the lecturer may have given about the test to ensure that the quality of knowledge and skills instilled in them are maintained even after 
completion of their studies. ${ }^{[17]}$ The same research has also shown that providing students with tools and strategies that build both emotional skills and healthy physical habits when preparing for a test can help them overcome test anxiety and the associated symptoms, while improving their ability to prepare for and perform on critical testing. ${ }^{[1]}$ On the other hand, Ayob and colleagues ${ }^{[18]}$ state that examination timetabling has an influence on the academic performance of students in a sense that if a timetable is well planned students have a better chance to perform well.

\subsubsection{Socio-economic factors}

Participants in this research indicate that problems in the relationship affect the student's academic performance. The problems that were identified are pregnancy, peer pressure and problems at home. Pregnancy in participants' opinion is the cause for a student to lag behind with her study and to repeat a module or a level. Pregnancy has a direct influence on the student's academic performance because it leads to school drop-outs, poor performance and interrupted class attendance due to hospital admission for delivery resulting in inability for a student to complete a study on time. ${ }^{[10]}$

Howard $^{[19]}$ highlights that peer influence are of a great concern to the academic performance of students. Peer influence results in absenteeism, poor study habits, incidence of examination malpractices and lack of concentration among students which influence academic performance and sometimes peer pressure shifts from academic to social issues such as smoking and drinking. ${ }^{[20,21]}$ It was indicated that lecturers expect students to behave in a certain way that is consistent with their peer group affiliation; thus, lecturers do not try to intervene when it comes to peer influence. ${ }^{[19]}$ To diminish peer influence, it was suggested that school authorities and parents need to monitor student activities. ${ }^{[20]}$ Furthermore, Namale and Ngaaso ${ }^{[20]}$ state that group counseling needs to be organized for students who are in relationship with peers to assist them in improving their academic performance. Howard ${ }^{[19]}$ also suggests that lecturers need to invest more energy in getting to know their students and which group they belong.

Problems in the relationship such as lack of support and assistance from friends and family members can affect the academic performance of the student; this can cause emotional problems, lack of concentration in class and lack of confidence in everything that the student is doing. ${ }^{[3,22]} \mathrm{Re}-$ searchers found that improper guidance from both the parents has a negative impact on students' academic performance. ${ }^{[23]}$ Some students are lazy and used to be pushed by parents to study constantly and to work hard; they enjoy their new freedom instead of studying or completing homework when they

Published by Sciedu Press are no longer under the supervision of their parents. ${ }^{[24]}$

Furthermore, participants indicate that socio-economic status of the students affects the quality of their mental and physical well-being which in turn influences their academic performance. ${ }^{[25]}$ The study by Farooq and colleagues ${ }^{[22]}$ revealed that students with financial problems have a poor academic performance because they cannot afford to buy prescribed books and their basic needs remain unfulfilled.

It is observed that low socio economic level of parents is negatively affecting the students' academic performance because it hinders the students' access to sources such as water and electricity as well as resources of learning. ${ }^{[22]}$ It was revealed that economically disadvantaged parents are less able to afford the cost of education of their children and consequently they (children) do not perform at their fullest potential. ${ }^{[22,23]}$

\subsection{Internal factors}

\subsubsection{Students' attitude towards lecturers and own study}

Participants in this research indicate that the attitude of the students towards some lecturers and their own study can influence their academic performance. Mbugua and colleagues ${ }^{[3]}$ state that the attitude and resistance of the student towards some lecturers and certain modules can contribute to poor academic performance while a student who has favourable attitudes towards a module can perform well academically.

The perceptions and expectations of the students about their lecturers are that they are experts, dedicated, supportive, hardworking and knowledgeable about the subjects they teach and when the students' expectations are not fulfilled students start to develop attitudes against the lecturer that influence their academic performance. ${ }^{[5]}$ Tom and colleagues ${ }^{[5]}$ further indicate that the diversity in socio-cultural background and language differences of both students and lecturers might influence the academic performance of nursing students. It is within that diversity of culture, background and language that a lecturer tries to facilitate learning for all the students but some students portray attitudes towards the lecturers. Some students "bully" their lecturers or call them "names" which leads to the student to develop an attitude towards the lecturer and in turn leads to poor academic performance.

According to Kumar, ${ }^{[26]}$ the student learns when he/she is willing and intends to learn and when knowing the purpose of learning. It is when the student accepts those goals that the student becomes more active, more intensive and better organised in pursuing those goals. ${ }^{[26]}$ One study conducted by Diaz $^{[27]}$ reveals that students need to develop a positive academic self-concept through internalization of their social image in order to fulfill their goals. 
To assist the student's attitude, motivation and interest in any module, lecturers need to observe the student's way and method in following learning process and participation in class activities. ${ }^{[28]}$ In order to improve the academic performance, the students need to develop favourable attitudes towards lecturers and module or the course because once students are motivated their attitudes towards the school work, self-confidence and personality is developed and enhanced. ${ }^{[3]}$

\subsubsection{Lack of self-discipline}

Participants indicate that students who lack self-discipline and self-confidence are likely to acquire problem behaviour from their peers such as absenteeism, substance abuse and paying less time on their school work which influence their academic performance. ${ }^{[29]}$ Students with high level of selfdiscipline perform well academically compared to students with low to moderate level of self-discipline. ${ }^{[30]}$

Indiscipline students are likely to lack self-motivation, do not focus on long term goals and they do not make better choices related to academic engagement. ${ }^{[31]}$ Lack of self-discipline among students results in poor student-lecturer relationship, time wastage for both undisciplined and disciplined students, ineffective learning and poor peer adjustment. ${ }^{[32]}$ Furthermore, Njoroge and Nyabuto ${ }^{[32]}$ highlighted that lack of selfdiscipline disrupts learning environment and entire effective management of the school.

\section{Conclusion}

It can be concluded that the academic performance of students is influenced by external factors such as teaching and learning related factors, insufficient resources, lack of university accommodation, curriculum related factors and socioeconomic factors as well as internal factors such as students' attitude and lack of self-discipline. In order to minimize these factors, a thorough assessment needs to be conducted. The assessment will include students' time management skills, study skills, stress management skills, expectation of nursing school and the nursing field from the student, family responsibilities of the student, access to technology and the student's activities outside the school. Such assessment can assist lecturers to give more support to the students so that they can develop effective study skills and complete their study within allocated time frame. This can reduce failure rate and overcrowding of some classes.

\section{ACKNOWLEDGEMENTS}

The authors would like to thank the management of UNAM, Oshakati campus for allowing them to conduct the research, the participants for their time and their willingness to participate in the research as well as everyone who contributed to the success of this study.

\section{CONFlicts OF INTEREST Disclosure}

The authors declare that they have no competing interests.

\section{REFERENCES}

[1] Van Dyk A. The history of nursing in Namibia. Windhoek: Gamsberg Macmillan Publishers (Pty) Ltd; 1997.

[2] Ganyaupfu EM. Teaching methods and students' performance. International Journal of Humanities and Social Science Invention. 2013 Sep; 2(9): 29-35.

[3] Mbugua ZK, Kibet K, Muthaa GM, et al. Factors contributing to student's poor performance in Mathematics at Kenya Certificate of Secondary Education in Kenya: A case of Baringo County, Kenya. American International Journal of Contemporary Research. 2012 Jun; 2(6): 87-91.

[4] Rane ZA. Factors that influence students learning achievement. [Internet]. Rumah Anthares Cari Blog Ini 2010 [cited 2010 Sept 19]. Available from: http://rumahanthares.blogspot.com/2010/ 09/factors-that-influence-students.html

[5] Tom F, Coetzee I, Heyns T. Factors influencing academic performance in biological sciences among students in a nursing education institution in the Eastern Cape Province: An appreciative inquiry approach. African Journal for Physical, Health Education, Recreation and Dance. 2014 Sept; supplement 3: 102-115. Available from: http://reference.sabinet.co.za/document/EJC162341

[6] Ganyaupfu EM. Factors influencing academic achievement in quantitative courses among business students of private higher education institutions. Journal of Education and Practice. 2013; 4(15): 57-65.
[7] Gillespie M. Student-teacher connection in clinical nursing education Issues and innovations in nursing education. Journal of Advanced Nursing. 2002 March; 37(6): 566-576. Available from: http:// gateway1.ovid.com:80/ovidweb.cgi PMid:11879421 https : //doi.org/10.1046/j.1365-2648.2002.02131.x

[8] Ali S, Haider Z, Munir F, et al. Factors contributing to the students' academic performance: A case study of Islamia University SubCampus. American Journal of Educational Research. 2014; 1(8): 283-289. https://doi .org/10.12691/education-1-8-3

[9] Owoeye JS, Yara PO. School facilities and academic achievement of secondary school agricultural science in Ekiti State, Nigeria. A Sian Social Science. 2011 Jul; 7(7): 64-74.

[10] Jafta MG. Perceptions of tutors and student nurses on factors that influence academic performance at the college [dissertation]. [Free State]: University of Free State; 2013. 224 p.

[11] Mokgaetsi SR. Factors contributing towards poor performance of grade 12 learners at Manoshi and Mokwatedi High schools. A minidissertation for a Master's degree in Development (unpublished). [dissertation]. [Limpopo]: University of Limpopo; 2009. 113 p.

[12] Listphoria. Don't blame teachers! Factors that influence student learning. Internet] Listphoria 2011. [Cited 2011 Aug 11]. Available from: http://listphoria.blospot.com/2011/08/fac tors-that-influence-student-learning.html 
[13] Tanvi J. How environmental factors affects our learning process. [Internet]. Preservearticles.com 2011 [cited 2011 Aug 29]. Available from: http://www.preservearticles.com/2011082912251 /how-environmental-factors-affects-our-learning-p rocess.html

[14] Ogedele PM. Internet usage and students' academic performance in Nigeria tertiary institutions. A case study of University of Maiduguri. Academic Research International. 2012 May; 2(3): 334-343.

[15] South African commercial Prop News. Demand for student accommodation spikes in South Africa South Africa Commercial Prop [Internet]. 2012 [cited 2012 June].

[16] Penprase BB, Harris M, Qu X. Academic success: Which factors contribute signify-cantly to NCLEX-RN success for ASDN students? Journal of Nursing Education and Practice. 2013 Jan; 3(7): 1-8. http://dx.doi.org/10.5430/jnep.v3n7p1

[17] Miller DM, Linn RL, Gronlund ENE, et al. Measurement and assessment in teaching. USA: Pearson; 2009.

[18] Ayob M, Abdullah S, Malik AMA. A practical examination timetabling problem at the university Kabangasaan Malaysia. IJCSNS International Journal of Computer Science Network Security. 2007 Sept; 7(9): 198-204. Available from: http://paper.ijcsns .org/07_book/200709/20070929.pdf

[19] Howard NM. Peer influence in relation to academic performance and socialization among adolescents: A literature review. A research paper submitted in partial fulfillment of Masters of Science degree with a major in school Psychology; 2004 May 30; University of Wisconsin-stout.

[20] Namale MK, Ngaaso CK. The influence of peer relations on the academic performance of students in high schools in Bolgatanga municipality in upper East region, Ghana. Journal of Research and Development in Education. 2012; 10: 133-141.

[21] Johnson KA. The peer effect on academic achievement among public elementary school Students. Heritage Centre for Data Analysis Heritage Foundation, 214. Washington; 2000 May.

[22] Farooq MS, Chaudhry AH, Shafiq M, et al. Factors affecting students 'quality of academic performance: A case of secondary school level. Journal of Quality and Technology Management. 2011 Jan; V11(11): 01-14. Available from: https://www.researchgate.n et/.../284150574
[23] Mushtaq I, Khan SN. Factors affecting students' academic performance. Global Journal of Management and Business Research. 2012 Jun; 12(9): 17-22. Available from: https://pdfs. semanticscholar.org/.../25923a3873037 204abdc494ea59b54b14b67.pdf

[24] Cheriff AH, Movahedzadeh F, Adams GE, et al. Why do students fail? Students' perspective. A collection of papers on self-study and institutional improvement. 2013 Annual Conference of the Higher Learning Commission; 2013 April 5-9; Hyatt Regency Chicago, Chicago: Higher Learning Commission; 2013. 35-51 p.

[25] Nnamani CN, Dikko HG, Kinta LM. Impact of student's financial strength on their academic performance: Kaduna Polytechnic experience. An International Multidisciplinary Journal, Ethiopia. 2014 Jan; 8(1): 83-89.

[26] Kumar S. What are the factors that affect learning? [Internet] Know cliff education for all 2015 [cited 2015 Jul 19]. Available from: http://www.publishyourarticles.net/knowledge-h ub/education/what-are-the-factors-that-affe

[27] Diaz AL. Personal, family, and academic factors affecting low achievement in secondary school. Electronic Journal of Research in Educational Psychology and Psychopedagogy. 2003 Jan; 1(1): 43-66.

[28] Shoebottom P. The factors that influence the acquisition of a second language [Internet]. 1996-2016 [cited 2016] Available from: http://est.fist.edu

[29] Thill RF. The importance of self-discipline for success in school [ Internet]. Self-discipline and your tween's school success 2016 [cited 2016 July 29].

[30] Simba ON, Agar JO, Kabuka E. Impact of discipline on academic performances of pupils in public primary schools in Muhoroni subcountry, Kenya. Journal of Education and Practice. 2016; 7(6): 164173.

[31] Laitsch D. Self-discipline and student academic achievement. Research Brief. 2006 June; 4(6).

[32] Nyoroge PM, Nyabuto AIN. Discipline as a factor in academic performance in Kenya. Journal of Education and Social Research. 2014 Jan; 4(1): 289-307. 